\title{
Amylosporus campbellii (Berk.) Ryvarden (Bondarzewiaceae, Basidiomycota), new record to Europe
}

\author{
Bernicchia $\mathrm{A}^{\mathbf{1}}$, Genovese $\mathrm{R}^{2}$ and Gorjón $\mathrm{SP}^{3}$ \\ ${ }^{1}$ Via Alessandro Guidotti 39, 40134 Bologna, Italy, corticia.polypores@gmail.com \\ ${ }^{2}$ Via Luigi Cassia 81A, Siracusa 96100 Sicily, Italy \\ ${ }^{3}$ Department of Botany and Plant Physiology, University of Salamanca, 37007 Salamanca, Spain, spgorjon@usal.es
}

Bernicchia A, Genovese R, Gorjón SP 2017 - Amylosporus campbellii (Berk.) Ryvarden (Bondarzewiaceae, Basidiomycota), new record to Europe. Mycosphere 8(1), 98-101, Doi $10.5943 /$ mycosphere/8/1/8

\begin{abstract}
The very interesting finding of a subtropical species, Amylosporus campbellii, is reported from Sicily, Italy. Macro-, microscopical characteristics, photographs, and comments on distributional patterns are given.

Key words - Italy - polypores - Russulales

\section{Introduction}

The research on the presence, distribution and ecology of Aphyllophorales in Italy started many years ago but sometimes we have found some species not reported before. It is the case of the interesting finding of Amylosporus campbellii, an extra European polypore, defined by Gilbertson \& Ryvarden (1986) "apparently a subtropical species". It is new to European mycota and very far from the other collecting areas that are located in Jamaica, Bermuda, Brazil, Venezuela, Nigeria, Kenya, Tanzania, Pakistan, Sri Lanka (Ryvarden \& Johansen 1980), California, Arizona, Texas and Florida (Gilbertson \& Ryvarden 1986), Mexico (Esqueda et al. 1995), Martinique in the Lesser Antilles (David \& Rajchenberg 1985), Costa Rica (Carranza \& Ruiz-Boyer 2005), India (Roy \& De 1996), Taiwan (Chang \& Chou 2003), Myanmar (Thaung 2015), and southern China (Dai 2007).
\end{abstract}

\section{Materials \& Methods}

\section{Isolates and morphology}

The specimen is deposited at the private Herbarium of the authors and at Herbarium SALA. The sections of the basidioma have been observed in 3\% and 5\% $\mathrm{KOH}$, Melzer's reagent (IKI) and $0.1 \%$ cotton blue in $60 \%$ lactic acid (CB) to determine cyanophily of basidiospore walls, using a Leitz phase contrast microscope and Leica light microscope. Microphotographs were taken using a Nikon Optiphot light microscope and a Leica DFC 290 camera.

\section{Results}

Amylosporus campbellii (Berk.) Ryvarden, Norw. J. Bot. 24: 217, 1977.

Figs $1-5$

$\equiv$ Polyporus campbellii Berk., Hook. J. Bot. 6: 228, 1854. 
Macroscopical characteristics - Basidiomes annual, sessile, semicircular, single but some of them confluent and somewhat overlapping, forming a large agglomerate that, at maturity, reach 30$50 \mathrm{~cm}$ in diam in the largest ones and to $20 \mathrm{~cm}$ in the smallest ones, $2-8 \mathrm{~cm}$ thick. It takes about 2030 days to attain the complete development. The sterile surface is pure white, soon then with pinkish shadows at least in the marginal parts, smooth, furrowed, tuberculate but azonate when fresh, unchanging when touched, light ochraceous when dry. The margins are lobate, wavy and obtuse, very light pinkish shade when fresh, light ochraceous when old. Stipe rudimentary. Context homogeneous but somewhat slightly zonate, white, watery and fleshy when fresh, very pale ochraceous and fragile when dry, up to $7 \mathrm{~cm}$ thick. Pore surface white when fresh, cream to ochraceous when dried, darker than the context, tubes up to $1 \mathrm{~cm}$ thick concolour with the pore surface; pore round to angular 2-4 per $\mathrm{mm}$ with lacerate dissepiments. Sterile surface and context have no reaction to Melzer's reagent while tubes and pore surface become bluish. The smell is very unpleasant, a mix of some different indefinite components. The disagreeable smell disappears on drying and turns to a typical fungal smell.

Microscopical characteristics - Hyphal system dimitic: generative hyphae hyaline, very thinwalled, with rare branches, simple septate but also with clamps that are single, double and sometimes verticillate 3-9 $\mu \mathrm{m}$ in diam, easily collapse and are IKI-. Skeletal hyphae thick-walled, aseptate, 4-6 $\mu \mathrm{m}$, straight or more or less flexuous, contorted, with a narrow lumen to subsolid and typical branches: the new branch becomes thinner in the apical part and sometimes it is dichotomously branched with short branches, 2-4 $\mu \mathrm{m}$ in diam and IKI-. Gloeoplerous hyphae present, more abundant in the context, flexuous, with some rare branches, thin to light thick-walled, filled with refractive content, hyaline with $\mathrm{KOH}$, yellowish with Melzer's reagent, 6-15 $\mu \mathrm{m}$ in diam. Cystidia and cystidiols absent while basidiols smaller than basidia are present. Basidia clavate, hyaline, thin-walled, with a simple septum at the base, with 4 sterigmata, $12-20 \times 6-8 \mu \mathrm{m}$, soon collapsed. Basidiospores numerous, hyaline, broadly ellipsoid, firm walled, so finely echinulate that the ornamentations are not easily seen, amyloid, (4-)4.5-5.5(-6) $\times(2.8-) 3-4(-4.5)$ $\mu \mathrm{m}, \mathrm{L}=4.99 \mu \mathrm{m}, \mathrm{W}=3.66 \mu \mathrm{m}, \mathrm{Q}=1.36 \mu \mathrm{m}(\mathrm{n}=30)$.

Specimen examined - Italy, Sicily, Harbour of Syracuse, $50 \mathrm{~m}$ far from the sea, growing on the ground but all around a shrub of Myrtus communis L. (Myrtaceae), leg. Roberto Genovese, 25 Aug. 2016 (coll. SPG 3673, in SALA). It appeared just after the first summer rains, collapsed after a month and didn't grow again during the autumn.

\section{Discussion}

Amylosporus campbellii is the first European finding, a very interesting record because this is very far from the typical growing areas that are the tropical and subtropical areas of Africa, southern North America, Central and South America, and South East Asia. The presence of double and multiple clamps is a peculiar characteristic of this species and unusual in polypores.

Records of unusual species have not been so unusual during the last years in the largest Italian Islands of Sardinia and Sicily, in which, year after year, findings that do not belong to European mycota have been reported with some frequency. This is the case for Macrocybe titans (H.E. Bigelow \& Kimbr.) Pegler, Lodge \& Nakasone, Macrocybe lobayensis (R. Heim) Pegler \& Lodge, Lactocollybia epia (Berk. \& Broome) Pegler, Leucocoprinus fragilissimus (Berk. \& M.A. Curtis) Pat., Clathrus chrysomycelinus Möller, and Colus hirudinosus Cavalier \& Séchier.

These interesting findings may surely be explained by numerous and various factors, but one of them is probably the changing of climatic conditions. During the last 12 years, the climate situation has changed, in the sense that over the Mediterranean region, previously dominated by both the Azores and the Russian anticyclones, the tropical or subtropical anticyclone has now taken over. Consequently, much rain arrives with the African wind currents, which over the Mediterranean become saturated with vapor and are then followed by warm Saharan flows, a purely subtropical-like situation. 

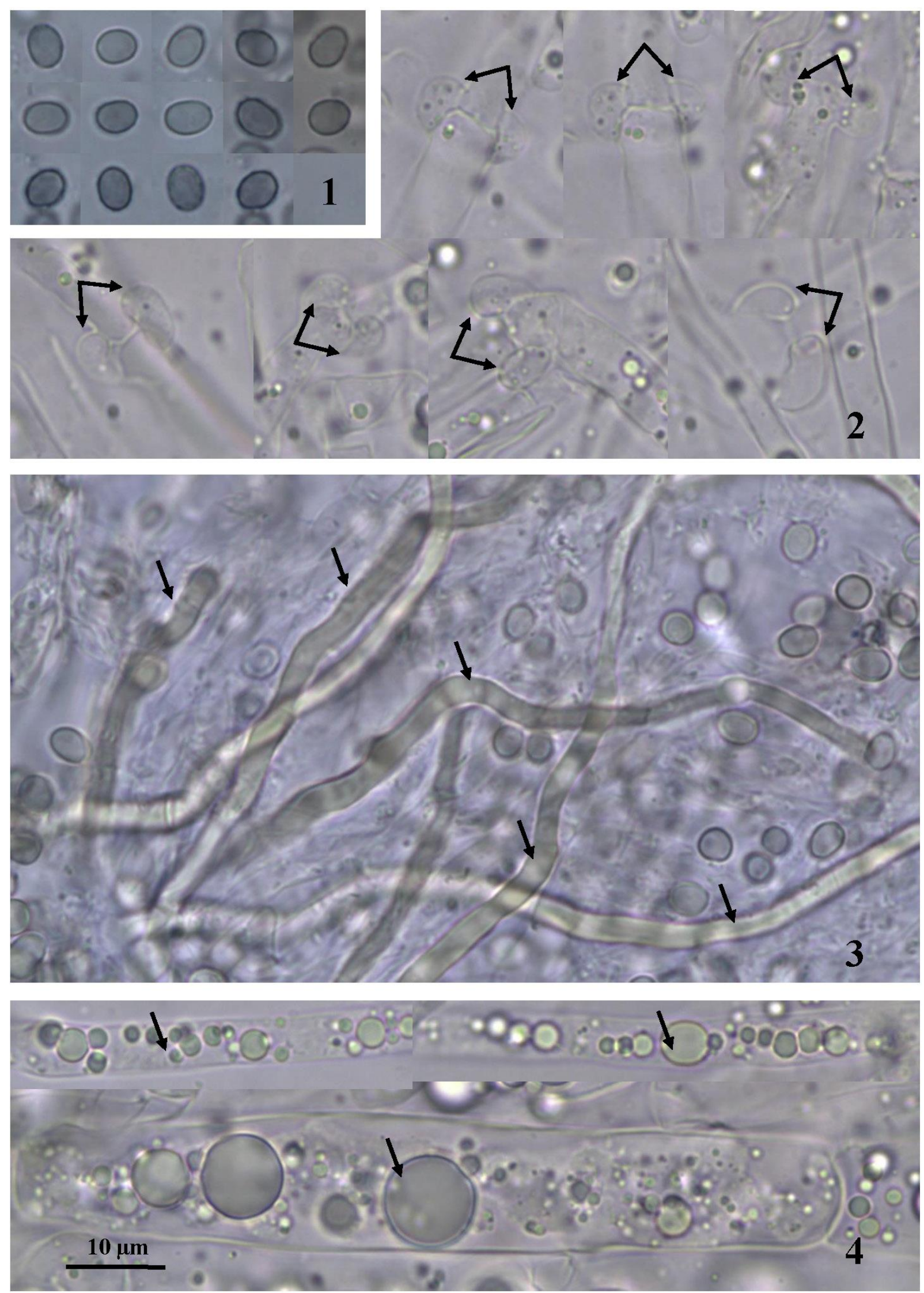

Figures 1-4-Amylosporus campbellii. 1 Basidiospores (in Melzer's reagent). 2 Hyphae with verticillate clamps (in $\mathrm{KOH}$ ). 3 Skeletal hyphae (in $\mathrm{KOH}$ ). 4 Gloeoplerous hyphae (in $\mathrm{KOH}$ ). 


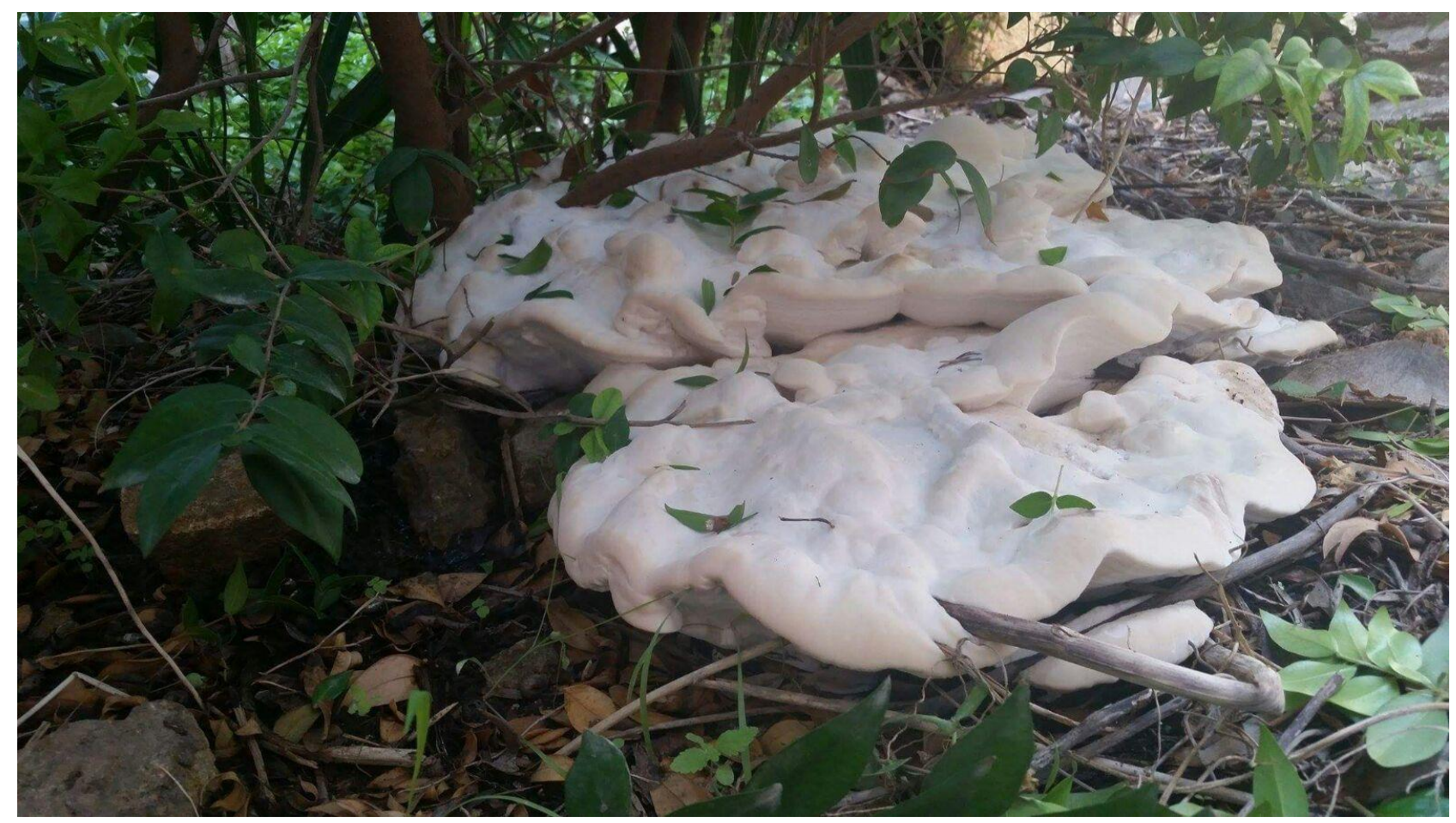

Figure 5 -Amylosporus campbellii. 5 Basidiomes in the habitat.

\section{Acknowledgements}

The authors would like to thank Dr. Nicola Amalfi by some data on the collections made in Sicily in recent years and the anonymous reviewers for linguistics improvements.

\section{References}

Carranza J, Ruiz-Boyer A. 2005 - Checklist of polypores of Costa Rica. Revista Mexicana de Micología 20, 45-52.

Chang TT, Chou WN. 2003 - Five polypores (Basidiomycota) new to Taiwan and their cultural characteristics. Botanical Bulletin of Academia Sinica 44, 245-251.

Dai YC. 2007 - Amylosporus campbellii, a noteworthy polypore new to Southerneast Asia. Czech Mycology 59, 171-175.

David A, Rajchenberg M. 1985 - Pore fungi from French Antilles and Guiana. Mycotaxon 22, 285-325.

Esqueda M, Pérez-Silva E, Villegas R, Araujo V. 1995 - Macromicetos de zonas urbanas, II: Hermosillo, Sonora, México. Revista Mexicana de Micología 11, 123-132.

Gilbertson RL, Ryvarden L. 1986 - North American Polypores I. Abortiporus - Lindtneria, 433p, Fungiflora, Oslo, Norway.

Roy A, De AB. 1996 - Polyporaceae of India, 287p. Dehra Dun.

Ryvarden L, Johansen I. 1980 - A preliminary polypore flora of East Africa, 636 p., Fungiflora, Oslo, Norway.

Thaung MM 2015 - A taxonomic analysis of miscellaneous fungi collected from Burma. Mycosphere 6, 8-12. 